\title{
Contribuições da Paisagem Rural e Urbana para Práticas Pedagógicas de Educação Ambiental
}

Contributions of the Rural and Urban Landscape to Pedagogical Practices of Environmental Education

Contribuciones del Paisaje Rural y Urbano para Prácticas Pedagógicas de

Educación Ambiental

\author{
Wallace Ancelmo dos Santos \\ Mestrando, UMC, Mogi das Cruzes. \\ wallace_sax@hotmail.com \\ Luci Mendes de Melo Bonini \\ Professora Doutora, UMC, Mogi das Cruzes. \\ lucibonini@gmail.com \\ Ricardo Sartorello \\ Professor Doutor, UMC, Mogi das Cruzes. \\ risartorello@gmail.com
}




\section{INTRODUÇÃO}

O estudo dos problemas ambientais, por meio da paisagem, é um modelo que proporciona uma representação do Meio de Vida do Homem sobre seu ambiente, sua atividade humana e sua trajetória. Para Santos (2002), a paisagem é um conjunto de formas, que exprime as relações entre homem e natureza, e este modelo tem sido utilizado pelos professores que se interessam pela Educação Ambiental sob o ponto de vista da Geografia ou das Ciências Humanas (SAUVÉ, 2005).

Atualmente, a Educação Ambiental nas escolas segue, muitas vezes, padrões propostos pelos livros didáticos e pelo currículo escolar, e a concepção dos professores, em decorrência disto, influencia as suas práticas pedagógicas, reforçadas pelas experiências no magistério, formação acadêmica e ambiente escolar (GAZZINELLI, 2002). Nesse sentido, Campiani (2001), afirma que o professor ${ }_{2}$ precisa ter os conceitos e metodologias que venham ao encontro da realidade, para atuarem de forma crítica sobre os problemas socioambientais.

Para Lima (2004), a escola é um espaço para conexões e informações, que deve estimular os alunos a despertar para a responsabilidade de que fazem parte do meio ambiente. Assim, a escola se torna um espaço de análise da natureza, contextualizando as práticas sociais complexas próximas da realidade social dos alunos, a fim de estabelecer uma relação harmoniosa entre os indivíduos e o meio ambiente (JACOBI, 2009).

Para Santos (2004), outra forma para estudar os problemas ambientais é a inserção de uma disciplina, nos currículos, que esteja relacionada à Paisagem, e neste caso, a Educação Ambiental seria uma aliada na construção de uma percepção ambiental mais acurada nos alunos, voltando-se para a complexidade das dinâmicas sociais urbanas e rurais relacionando preservação e conservação dos recursos naturais. Nessa mesma perspectiva, Melazo (2009), afirma que Educação Ambiental - e consequentemente as práticas pedagógicas - devem estar ligadas à paisagem local para fortalecer as relações pessoais com as paisagens culturais.

Essa necessidade de estabelecer relações entre a Educação Ambiental e a Paisagem, pode contribuir para solucionar os problemas ambientais locais, pois segundo Jacobi (2009), quando as condutas cotidianas que afetam a sociedade sofrem interferências por meio da Educação Ambiental, novas leituras da realidade são promovidas. O autor também sugere que a noção de currículo vivido no cotidiano, facilita a contextualização de saberes, a partir da valorização das culturas locais, valores e experiências que proporcionem uma mobilização comunitária para construir ações para a sustentabilidade. Na geografia, por exemplo, professores buscam trabalhar os assuntos voltados para o meio ambiente por meio da leitura da paisagem como ferramenta para desenvolver experiências e relações entre alunos com o seu lugar vivido (VERDUM \& PUNTEL, 2010).

Assim, este estudo realiza uma análise de como a Paisagem Rural e Urbana utilizada nas práticas pedagógicas de educação ambiental de professores do Ensino Fundamental I da Rede Municipal de Ensino de Mogi das Cruzes - SP, auxilia a consciência da responsabilidade, da conservação e preservação do meio ambiente local. 


\section{METODOLOGIA}

Pesquisa exploratório-descritiva, de abordagem quanti-qualitativa de corte transversal. A pesquisa foi desenvolvida em 04 escolas, definidas por meio de mapeamento, duas escolas localizadas em Zona Urbana e duas em Zona Rural: a) duas em áreas com maior adensamento urbano; b) duas em áreas com remanescentes vegetais; em áreas próximas de cursos d'agua; e aspectos atuais de mudanças na paisagem. A coleta dos dados se deu por meio de entrevistas semiestruturadas com 31 professores do 10 ao 5을 do Ensino Fundamental I - gravadas e depois transcritas. As respostas foram categorizadas com base no método de análise de conteúdo de Bardin (2009). Neste trabalho, descrevem-se resultados preliminares da pesquisa: perfil de formação dos professores e como eles relacionam suas práticas pedagógicas em sala de aula.

\section{RESULTADOS}

Dos 31 professores que participaram da pesquisa, assim estão divididos no seu perfil de formação (Tabela 01).

Tabela 1: Perfil de Formação dos professores das escolas pesquisadas.

\begin{tabular}{c|c|c}
\hline $\begin{array}{c}\text { Formação Acadêmica em Nível } \\
\text { de Graduação e Magistério }\end{array}$ & $\begin{array}{c}\text { N o de Professores - Zona } \\
\text { Rural }\end{array}$ & $\begin{array}{c}\mathbf{N} \text { o de Professores - Zona } \\
\text { Urbana }\end{array}$ \\
\hline Pedagogia & 12 & 10 \\
\hline Magistério & 02 & 02 \\
\hline Pedagogia e Magistério & 02 & 03 \\
\hline Total & $\mathbf{1 6}$ & $\mathbf{1 5}$ \\
\hline
\end{tabular}

Fonte: dados da pesquisa.

Percebe-se que nenhum professor possui formação em Ciências do Ambiente, como a Biologia, Ciências Naturais ou Geografia. Essa é uma importante variável a ser discutida, embora não seja obrigatória uma formação específica, seria interessante que esses profissionais da educação tivessem alguma formação além da que apresentam para poder tratar dos problemas ambientais propostos pelo currículo escolar do Ensino Fundamental I.

Quando questionados se eles relacionam o meio ambiente das paisagens culturais do entorno da escola com os assuntos de educação ambiental, obtém-se as seguintes respostas: $87 \%$ dos professores de Zona Rural e $94 \%$ de Zona Urbana, desenvolvem essa relação em suas práticas pedagógicas.

No gráfico 01, observa-se a comparação percentual de cada categoria encontrada nas falas dos professores de Zona Urbana e Zona Rural sobre como eles relacionam suas práticas pedagógicas com o meio ambiente da paisagem rural e urbana. Podemos destacar que $27 \%$ dos professores de Zona Rural buscam dar enfoque, em suas aulas, nas as experiências, à vivência dos alunos e a proximidade da escola com o ambiente natural para contextualizar os problemas ambientais abordados em Educação Ambiental, propostos no currículo escolar. 


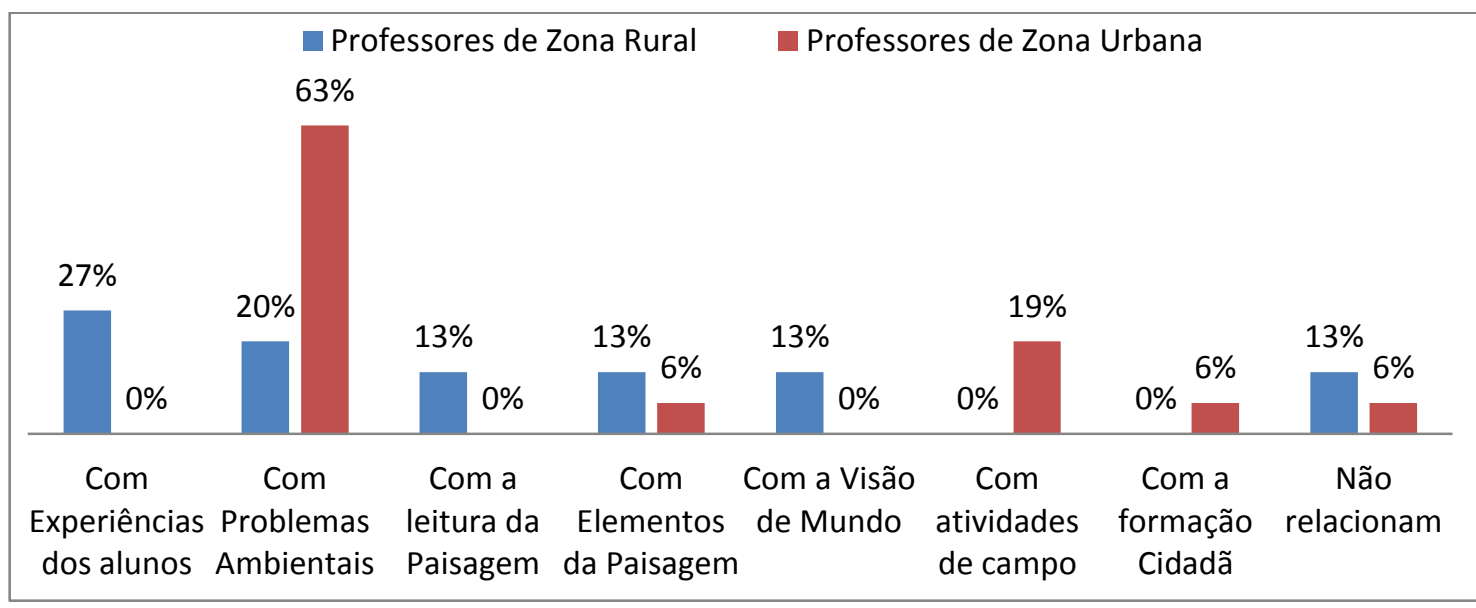

Fonte: dados da pesquisa.

Pode-se observar, na fala de um professor, o enfoque dado às experiências dos alunos com a paisagem:

\{...\} falando sobre meio ambiente, as... Os animais da região, as crianças vão citando, né? \{...\} até tem os "macaquinhos" que eles citam bastante, tem os tucanos, e a gente vai perguntando: quais são os animais que vocês costumam ver? O quê que vocês acham da nossa região? Que nem nós temos, é da nossa flora, da nossa fauna, das coisas que são produzidas na nossa região, a gente... $O$ cogumelo. A nossa região tem muito da parte da agricultura, as plantações, o cinturão verde, a gente fala bastante. [P1 Zona Rural]

Por outro lado, destaca-se o percentual de $63 \%$ de professores de Zona urbana que buscam relacionar os problemas ambientais e transformação da paisagem em suas práticas de educação ambiental. Isso pode estar relacionado com os problemas ambientais vivenciados por eles e pelos alunos, por estarem em um ambiente de transformação da paisagem, que os remetem a história da cidade e das transformações que ela vem sofrendo ao longo do tempo pelo homem, como podemos observar na fala de um dos professores:

Sim. Aqui por exemplo: a gente tem o "riozinho" que passa aqui em baixo, né? E ai assim, como eu moro no bairro há anos, né? Então, a gente percebe que de uns anos pra cá, a situação de enchentes tem ficado grave aqui, \{...\} Por que aumentou o numero de moradores, né? As casas ficam na encosta do rio, né? Então não tem aquele afastamento, vamos dizer assim: de proteção, né? Não tem esse afastamento, o rio tá cada vez mais estreito, por conta dessas habitações, e então, e ai vem: esgoto, né? Que sendo jogado nesse rio. Lixo. $\{. .$.$\} eu sempre falo muito com eles sobre, principalmente$ sobre isso, sobre a enchente $\{. .$.$\} . [P1 Zona Urbana].$ 


\section{CONCLUSÃO}

Os professores, mesmo de escolas em contextos de paisagens culturais diferentes, conseguem explorar os elementos presentes na paisagem, sejam eles de escolas com paisagem rural ou urbana. As práticas apresentadas pelos professores dão destaque aos elementos regionais e locais presentes na paisagem da cidade, como a Serra do Itapeti, Serra do Mar, Rio Tietê, Mata Atlântica e as Transformações da Paisagem e as experiências dos alunos com essas paisagens. Isso demonstra que mesmo não tendo um perfil de formação que tenha relação direta com as Ciências do Ambiente, como a Biologia, Ciências Naturais ou Geografia, os professores buscam, com auxílio das experiências que eles e os alunos possuem com as diferentes paisagens culturais, trabalhar em suas práticas pedagógicas a Educação Ambiental. Também ficou destacado que os professores de Zona Rural buscam utilizar as experiências dos alunos com a paisagem natural e, por outro lado, os professores de Zona Urbana, enfocam suas práticas nos problemas ambientais da cidade, ambos trabalhando a consciência da responsabilidade, da conservação e preservação do meio ambiente local.

\section{REFERÊNCIAS BIBLIOGRÁFICAS}

BARDIN, L. Análise de conteúdo. São Paulo: Edições 70, 2009.

CAMPIANI, Maximiano César. Os temas transversais na educação. São Paulo: Códex, 2001.

GAZZINELLI, M.F. Representação do professor e implementação de currículo em Educação Ambiental. Cadernos de Pesquisa. № 115 (173-194), março 2002.

JACOBI, Pedro Roberto et al. A função social da educação ambiental nas práticas colaborativas: participação e engajamento. Cadernos Cedes, v. 29, n. 77, p. 63-79, 2009.

LIMA, Waldyr. Aprendizagem e classificação social: um desafio aos conceitos. Fórum Crítico da Educação: Revista do ISEP/Programa de Mestrado em Ciências Pedagógicas. v. 3, n. 1, out. 2004. Disponível em: <http://www.isep.com.br/FORUM5.pdf>. Acesso em: 24 Junho. 2017.

MELAZO, Guilherme Coelho. Percepção ambiental e educação ambiental: uma reflexão sobre as relações interpessoais e ambientais no espaço urbano. Olhares \& Trilhas, 2009.

SANTOS, Edna Maria dos; FARIA, Lia Ciomar Macedo de. O educador e o olhar antropológico. Fórum Crítico da Educação: Revista do ISEP/Programa de Mestrado em Ciências Pedagógicas. v. 3,n. 1, out. 2004. Disponível em: <http://www.isep.com.br/FORUM5.pdf>. Acesso em: 22 Junho. 2017.

SANTOS, Milton. A natureza do espaço: técnica e tempo, razão e emoção. Edusp, 2002.

SAUVÉ, Lucie. Uma cartografia das correntes em educação ambiental. Educação Ambiental: pesquisa e desafios, p. 17-44, 2005.

VERDUM, Roberto; PUNTEL, Geovane Aparecida. Espaço geográfico e paisagem. Ensino fundamental, p. 75, 2010. 